\title{
Pulmonary vein stenosis after lung transplantation: a case report and literature review
}

\author{
Lei Jing ${ }^{1,2 \#}$, Wenhui Chen ${ }^{2 \#}$, Zhenguo Zhai ${ }^{3}$ Xin Pan $^{4}$, Xincao Tao ${ }^{3}$, Lei Cao ${ }^{2}$, Li Zhao ${ }^{2}$, Lijuan Guo ${ }^{2}$, \\ Chaoyang Liang ${ }^{2}$, Jingyu Chen ${ }^{2}$, Chen Wang ${ }^{1,2}$ \\ ${ }^{1}$ Chinese Academy of Medical Sciences and Peking Union Medical College, Beijing, China; ${ }^{2}$ Department of Lung Transplantation, Centre for Lung \\ Transplantation, Centre for Respiratory Diseases, China-Japan Friendship Hospital, Beijing, China; ${ }^{3}$ Department of Respiratory and Critical Care \\ Medicine, Centre for Respiratory Diseases, China-Japan Friendship Hospital, Beijing, China; ${ }^{4}$ Department of Cardiology, Shanghai Chest Hospital, \\ Shanghai, China \\ "These authors contributed equally to this work. \\ Correspondence to: Jingyu Chen; Chen Wang. No. 2 Yinghua East Road, Chaoyang District, Beijing 100029, China. Email: chenjy@wuxiph.com; \\ wangchen66366@163.com.
}

\begin{abstract}
Pulmonary vein stenosis (PVS) is a rare event following lung transplantation which increases the risk of morbidity and mortality. Early detection and rapid treatment of this condition is crucial for its management. Although several reports on PVS have been published, there is little consensus regarding its diagnosis and the methods of management. Here we present our experience with PVS. A 31-year-old man received a left lung transplant for chronic hypersensitivity pneumonitis. One year after his singlelung transplant, he began to develop persistent progressive hypoxemia. Computed tomography (CT) of the chest showed left pleural effusion and thickening of the interlobular septa. The results of bronchoscopy and transbronchial biopsies excluded the possibility of acute rejection or infection. The pleural effusion was transudative with lymphocyte predominance. Computed tomography angiography (CTA) in the left atrium and pulmonary veins demonstrated obvious stenosis of both the upper and lower left pulmonary veins (LLPVs) at the transplant anastomotic site. The patient underwent a catheter-guide stent implantation into the stenotic segment of the upper left pulmonary vein (ULPV), and his pleural effusion and hypoxemia problems were ameliorated. Ten months after the intervention, the patient was in excellent clinical condition. In a literature review, we discuss the importance of identifying PVS early after transplantation, the utility of CTA for diagnosis and the use of pulmonary vein stenting intervention. This review provides a basis for further diagnostic strategies and treatments for PVS following lung transplantation.
\end{abstract}

Keywords: Lung transplantation; pulmonary vein stenosis (PVS); diagnosis and management; case report

Submitted May 21, 2020. Accepted for publication Nov 01, 2020.

doi: 10.21037/atm-20-3972

View this article at: http://dx.doi.org/10.21037/atm-20-3972

\section{Introduction}

Lung transplantation remains as the only treatment for patients with end-stage lung disease. Vascular complications after lung transplantation occur in 1-3\% of patients and are associated with graft failure, retransplantation, and a high mortality rate $(1,2)$. These complications usually involve pulmonary artery complications or pulmonary vein thrombosis, however, case reports of pulmonary vein stenosis (PVS) are scarce (3). PVS increases vascular resistance of the stenotic vein and raises lobar capillary pressure, thus leading to symptoms such as dyspnea, hypoxemia and pulmonary lobar edema resulting in high mortality at advanced stages (4).

Clinically, the timely diagnosis of PVS is challenging and can often be missed because PVS presents with similar clinical symptoms to other post-transplant complications, such as reperfusion injury, infection, acute graft rejection 


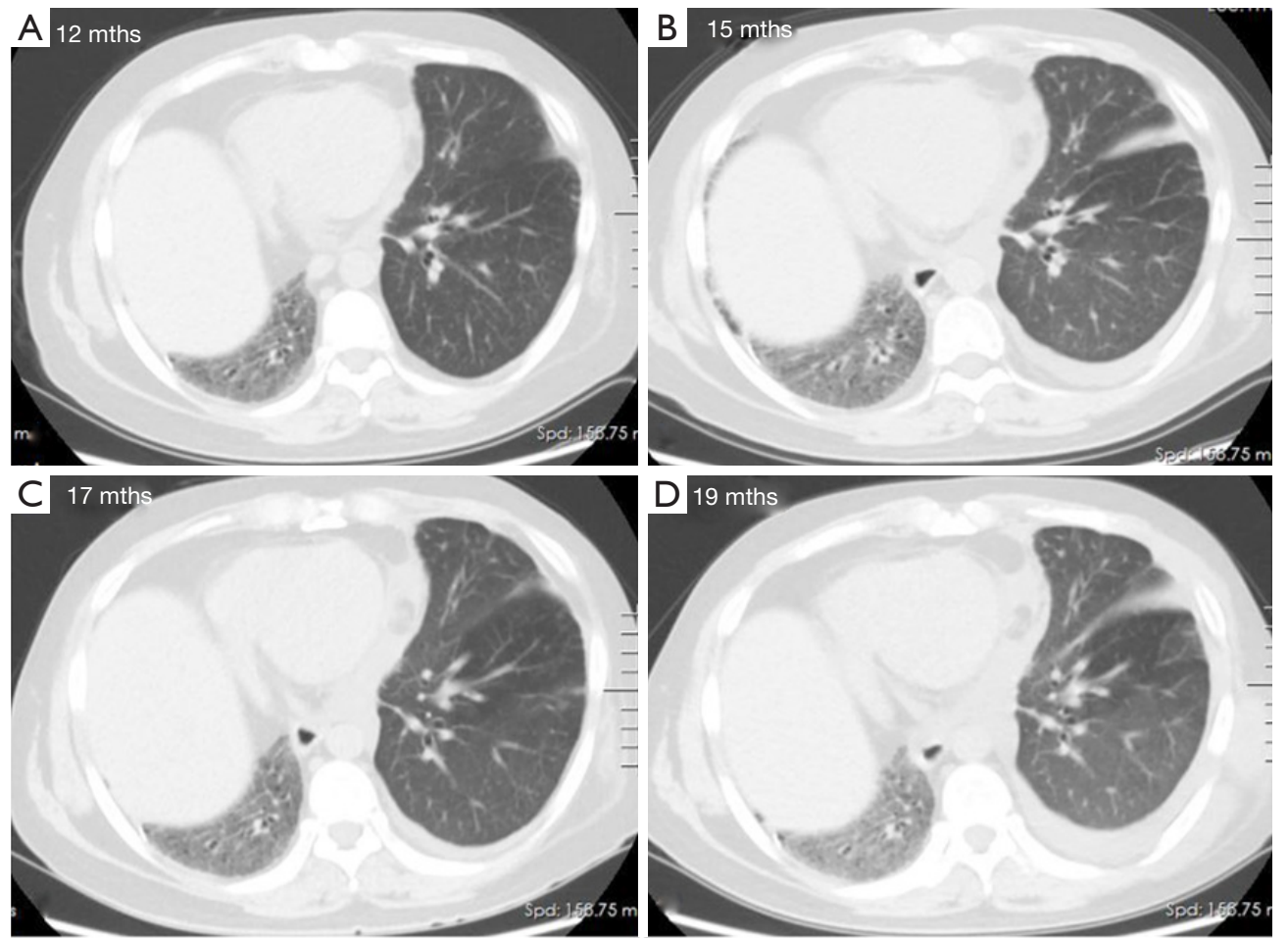

Figure 1 CT scan of the patient's lung area. (A) and (B) one year after transplantation there was a left pleural effusion and thickening of the interlobular septa; (C) partial reduction of left pleural effusion after infusion of furosemide and successful drainage; (D) the reaccumulated left pleural effusion. CT, computed tomography.

and cardiac insufficiency (5). Currently, there are no clear guidelines on the optimal diagnostic modality and treatment of patients with PVS following lung transplantation. Herein we describe our own experience with PVS in addition to a comprehensive review of the 18 cases reported in the literature. We discuss the clinical presentation of PVS, timing of diagnosis, optimal diagnostic modality, interventions and the outcomes. We present the following article in accordance with the CARE reporting checklist (available at http://dx.doi.org/10.21037/atm-20-3972) (6).

\section{Case presentation}

A 31-year-old man (height $178 \mathrm{~cm}$; weight $75 \mathrm{~kg}$ ) received a left lung transplant for chronic hypersensitivity pneumonitis. Veno-venous extracorporeal membrane oxygenation (VV-ECMO) was used to support the recipient during transplantation. During implantation of the left lung allograft, cardiac arrest occurred after the surgeon clamped the atria for cuff anastomosis. The heart resumed beating soon after release of the atrial clamp. Due to the uncontrollable cardiac arrest during atrial anastomosis, the upper and lower left pulmonary veins (LLPVs) were anastomosed with the corresponding donor veins instead of pulmonary cuff anastomosis. Further inspection of the operation site showed normal results. VV-ECMO was removed on postoperative day (POD) 3 , and the patient was successfully extubated on POD 5 . The patient was discharged 2 months after lung transplantation and recovered well.

One year after the transplant, he began to develop persistent progressive hypoxemia. Computed tomography (CT) of the chest showed left pleural effusion and thickening of the interlobular septa (Figure 1A,B). The results of bronchoscopy and transbronchial biopsies excluded the possibility of acute rejection or infection. The pleural effusion was transudative with lymphocyte predominance. An infusion of furosemide was initiated with only a partial resolution of the congestion (Figure 1C). However, the pleural effusion reaccumulated after several months (Figure 1D). Computed tomography angiography (CTA) in the left atrium and pulmonary veins demonstrated 

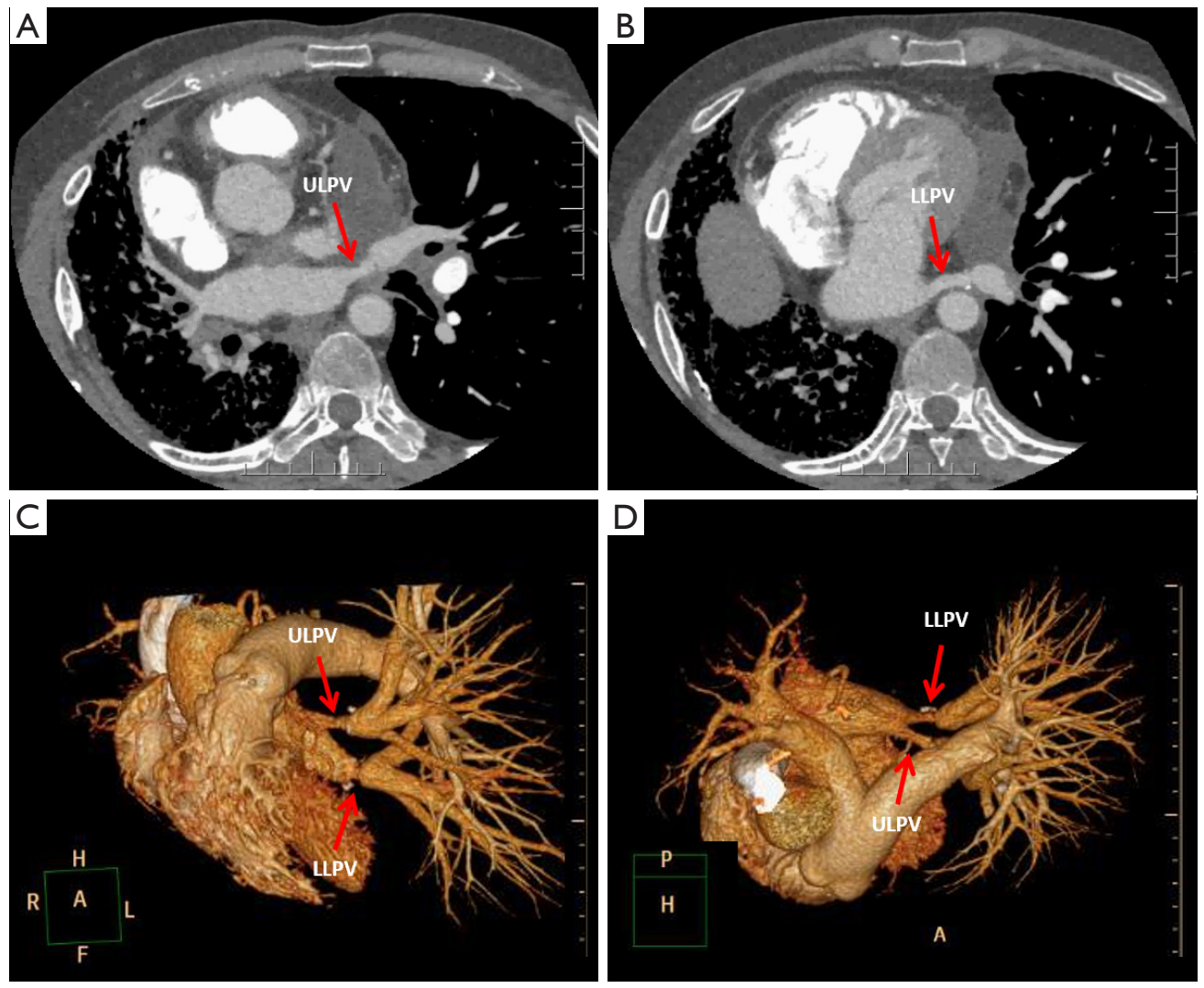

Figure 2 CTA of the left atrium and pulmonary veins show severe diameter reductions in the upper (A) and lower (B) left pulmonary veins. (C,D) 3D reconstruction. The stenosis is indicated by a red arrow. CTA, computed tomography angiography; ULPV, upper left pulmonary vein; LLPV, lower left pulmonary vein.

obvious stenosis of both the upper and LLPVs at the transplant anastomotic site, where the average luminal diameter was approximately 0.20 and $0.25 \mathrm{~cm}$, respectively (Figure 2).

Right heart catheterization and a stent placement were recommended; the patient agreed and provided consent. Bilateral femoral vein puncture was performed, then a $5 \mathrm{~F}$ MPA2 catheter (Cordis; a Johnson \& Johnson company; USA) was placed through the left femoral vein to the main pulmonary artery, and the pulmonary artery pressure was measured at 56/35 [43] mmHg. An 8F Swartz sheath (Swartz Braided SL1; St. Jude Medical, USA) was placed in the right femoral vein and advanced over the wire into the right atrium. This was followed by a transseptal puncture under $\mathrm{X}$-ray guidance. The Swartz sheath was then introduced into the left atrium. The upper left pulmonary vein (ULPV) anastomosis was located, and angiography measured approximately $90 \%$ stenosis.

The angiography catheter was sent to the distal end of the stenosis segment of the ULPV by the Runthrough NS guidewire (TERUMO, Japan). The Runthrough NS guide wire was then removed, and the Cordis guidewire (Cordis, a Johnson \& Johnson company; USA) was put to the left atrium and the distal end of the stenosis segment of the ULPV. The left atrial pressure was 20/5 [9] $\mathrm{mmHg}$, and the pressure at the distal end of the ULPV stenosis was 62/39 [49] mmHg. A 10×25 mm Express ${ }^{\circledR}$ LD vascular stent (Boston Scientific Corporation; Natick, Mass) was deployed into the stenotic segment at 16 atmospheric pressure (atm) (Figure 3), reducing the pressure of the ULPV to 32/18 [24] $\mathrm{mmHg}$. The pressure gradient between the distal end of the ULPV and left atrium decreased from 40 to $15 \mathrm{mmHg}$. Pulmonary artery pressure was then reduced to 40/23 [32] $\mathrm{mmHg}$. After stent deployment, a pulmonary angiography revealed that the obstruction of the ULPV had disappeared (Figure 4). Afterwards, we attempted to implant a second stent at the anastomotic stenosis of the LLPV but failed.

The patient tolerated the procedure well. Despite 

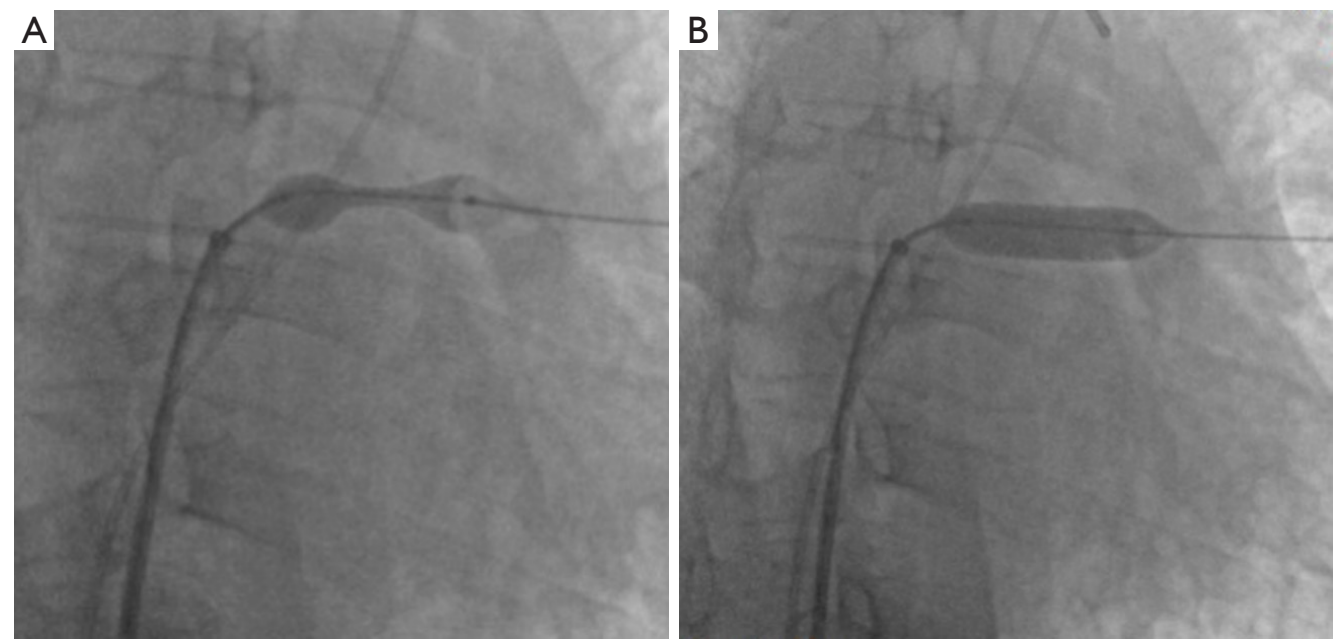

Figure 3 Angiograms show (A) release of the $10 \times 25 \mathrm{~mm}$ vascular stent and (B) the fully expanded stent.

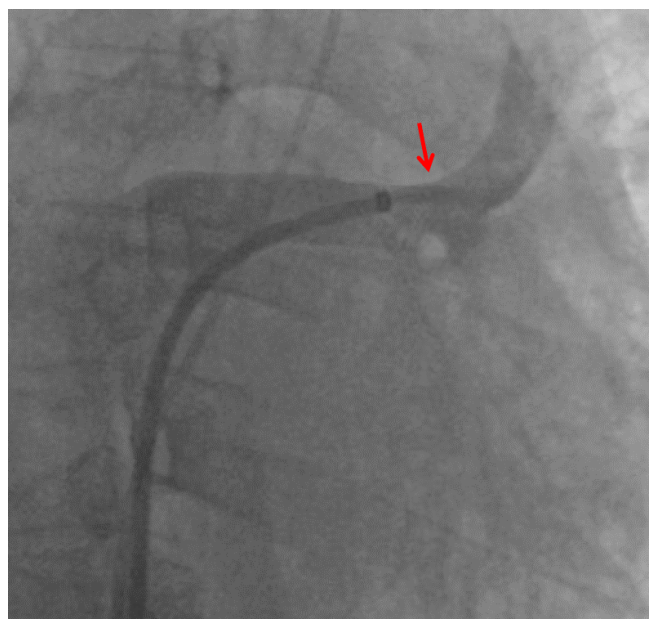

Figure 4 Pulmonary venogram shows no obstruction (arrow) after stent deployment. stent placement only in the ULPV, we observed a rapid improvement in his condition. Pleural effusion disappeared within 48 hours after stent placement, and the patient reported resolution of his shortness of breath. He was treated for 20 days with antithrombotic therapy that included low molecular weight heparin and warfarin followed by long-term treatment with warfarin and clopidogrel to maintain an international normalized ratio of 1.5 to 2 . The patient was discharged 20 days after stent placement. Ten months after intervention, the patient was in excellent clinical condition. No adverse or unanticipated events occurred during the whole process. The whole process of diagnosis and treatment of PVS was outlined in Figure 5. All procedures performed in this study involving human participants were in accordance with the ethical standards of the institutional and/or national research

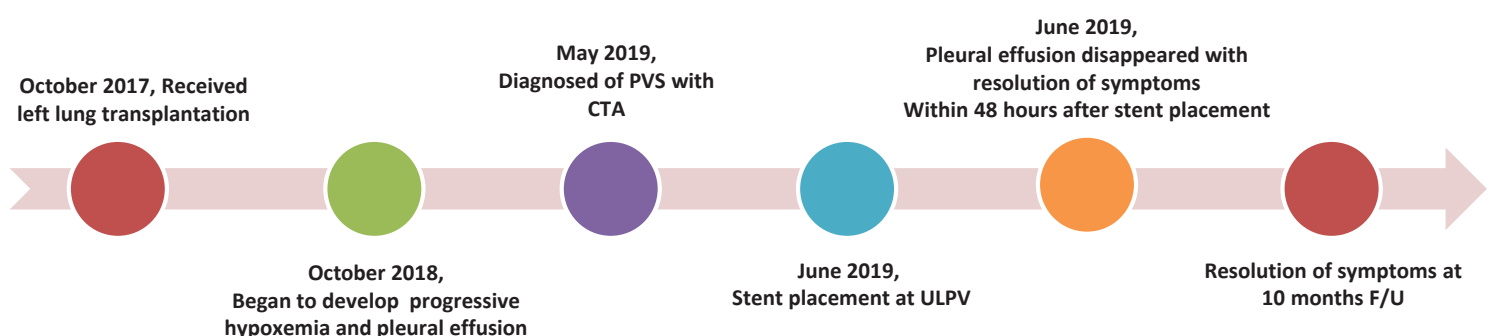

Figure 5 Timeline for diagnosis and treatment of pulmonary vein stenosis. PVS, pulmonary vein stenosis; CTA, computed tomography angiography; ULPV, upper left pulmonary vein; F/U, follow-up. 
committee(s) and with the Helsinki Declaration (as revised in 2013). Written informed consent was obtained from the patient.

\section{Discussion}

Although PVS is a well-known sequela of catheter-guided atrial fibrillation ablation procedure, it is a rare complication after lung transplantation. This may in part, explain the lack of consensus regarding the optimal diagnosis and management. Summarizing our current knowledge on PVS will help to establish best practices for its diagnosis and treatment.

There has been a total of 16 publications following 18 cases of PVS. This includes 10 case reports $(3,5,7-14)$ and 6 retrospective studies $(15-20)$. These studies are summarized in Table 1. Key study variables included patient demographics, time of diagnosis following transplantation, method of diagnosis, pulmonary vein parameters, clinical presentation, intervention used and outcomes.

Indications for PVS and primary graft dysfunction (PGD) are similar and include dyspnea, hypoxemia, recurrent pleural effusion, pulmonary edema and hemodynamic instability (9). Therefore, where severe PGD is suspected but patients do not show improvement with treatment, PVS should be considered.

Among publications, the timing of diagnosis of PVS fell into three categories: "intraoperative" (PVS discovered in the operating room before sternal closure), "early postoperative" (PVS discovered within the first 72 hours after lung transplantation) and, "late postoperative" (PVS discovered after the initial 72 hours) (2). PVS that occurred during the intraoperative or early postoperative period was likely due to surgical technique or graft anastomotic twist, while PVS that developed in the late postoperative period (especially more than 1 month postoperatively) was mainly due to scar hyperplasia at the anastomosis.

For the modality of diagnosis, CTA is the best noninvasive imaging modality and can provide accurate imaging for quantifying the severity of stenosis. CTA also has great value in surveillance after interventional treatment for the assessment of residual stenosis (4). Pulmonary angiography is thus far the gold standard for diagnosing PVS, as this approach can obtain hemodynamics and evaluate the efficacy of interventional treatment. In contrast to CTA/pulmonary angiography, TEE is the only modality that can be used intraoperatively for the diagnosis of PVS. The collected data showed that almost all intraoperative diagnoses of PVS were made by TEE due to its unique convenience (Table 1). However, data from the past decade [2009-2019] indicated that CTA is the most popular modality for confirming the diagnosis of PVS postoperatively (Table 1).

There is still a lack of consensus on the diagnostic criteria of PVS; a peak pulmonary vein anastomosis velocity of $\geq 1 \mathrm{~m} / \mathrm{s}$, a pulmonary vein luminal diameter of $<0.5 \mathrm{~cm}$, and/or a $>50 \%$ reduction in pulmonary vein diameter in comparison to the contralateral pulmonary vein may be indicative of PVS $(2,19)$. However, for a double lung transplant patient, it is more difficult to diagnose PVS according to the above standard due to lack of contralateral normal pulmonary venous control. In addition, using a $\geq 1$ $\mathrm{m} / \mathrm{s}$ peak pulmonary vein anastomosis velocity threshold for dysfunction may not be applicable after lung reperfusion due to the occurrence of hyperdynamic circulation (2). Using a pulmonary vein luminal diameter to diagnose PVS is also difficult due to the large variation caused by different tools and technical operation and the lack of clearly defined thresholds, which illustrate the need for comprehensive analysis and standardized diagnostic guidelines for PVS following lung transplantation.

Comparing the perioperative mortality rate of untreated PVS patients ( 1 of 2 patients, 50\%) $(9,17)$ with treated patients ( 2 of 17 patients, $11.8 \%)(3,5,7,8,10-20)$, it is suggested that the risk of patient mortality may be decreased by timely diagnosis and appropriate intervention. Retransplantation or open surgical repair to relieve stenosis increases the patient's risk of death, while stent implantation with or without balloon dilation offers a less invasive treatment and seems to have been performed more in recent years. Data showed that PVS patients who received stent placement with/without balloon dilation showed excellent outcomes $(3,5,11,12)$, while patients with balloon dilation as the only intervention method showed a high recurrence rate $(13,14)$. At present, there is no uniform standard for stent size selection, which is mostly performed by clinicians based on their experience. In our new case, we implanted a $10 \mathrm{~mm}$ stent to the stenotic site of the patient's ULPV, with the expectation that the larger diameter would ensure pulmonary vein reflux, improve pulmonary perfusion, and reduce the occurrence of long-term restenosis. The patient soon showed significant improvement in clinical status and was still in excellent condition at the 10-month follow-up.

To our knowledge, this is the first case report of PVS after lung transplantation and the first successful treatment of PVS by stent placement after lung transplantation in 
Table 1 Summary of previously reported cases and the current case of pulmonary vein stenosis (PVS) following lung transplantation

\begin{tabular}{|c|c|c|c|c|c|c|c|c|c|c|}
\hline Study & $\begin{array}{l}\text { Age (yrs) } \\
\text { gender }\end{array}$ & $\begin{array}{l}\text { Type of } \\
\text { transplant }\end{array}$ & Timing of diagnosis & $\begin{array}{l}\text { Modality of } \\
\text { diagnosis }\end{array}$ & $\begin{array}{l}\text { Location of } \\
\text { stenosis }\end{array}$ & $\begin{array}{l}\text { Pulmonary } \\
\text { vein diameter } \\
\text { (cm) (mean } \pm \\
\text { SD) }\end{array}$ & $\begin{array}{l}\text { Pulmonary vein } \\
\text { pressure gradient } \\
(\mathrm{mmHg})(\text { mean } \pm \mathrm{SD})\end{array}$ & $\begin{array}{l}\text { Clinical presentations: } 1 \text {. dyspnea and } \\
\text { hypoxemia; 2. pleural effusion; 3. pulmonary } \\
\text { edema; } 4 \text {. hemodynamic instability; } 5 \text {. other } \\
\text { or not described }\end{array}$ & Intervention & Outcome \\
\hline Low 1992 (7) & $54 \mathrm{M}$ & L-SLT & $\begin{array}{l}\text { Early postoperative } \\
\text { period }\end{array}$ & $\begin{array}{l}\text { Pulmonary } \\
\text { angiography }\end{array}$ & Left common PV & - & - & $1,2,3,4$ & Retransplantation & Resolution of symptoms at $18 \mathrm{mths} F / U$ \\
\hline \multirow[t]{2}{*}{ Haydock 1992 (15) } & - & R-SLT & Intraoperative & - & Right common PV & - & - & 5 & Open surgical repair & Resolution of symptoms at $6 \mathrm{mths} F / U$ \\
\hline & - & L-SLT & $\begin{array}{l}\text { Early postoperative } \\
\text { period }\end{array}$ & $\begin{array}{l}\text { Pulmonary } \\
\text { angiography }\end{array}$ & Left common PV & - & - & 1,3 & Retransplantation & Resolution of symptoms at $6 \mathrm{mths} F / U$ \\
\hline Griffith 1994 (16) & - & L-SLT & $\begin{array}{l}\text { Early postoperative } \\
\text { period }\end{array}$ & TEE & Left common PV & - & - & 1,3 & Open surgical repair & Discharge after $3 \mathrm{mths}$ \\
\hline Michel-Cherqui 1997 (19) & $52 \mathrm{M}$ & R-SLT & Intraoperative & TEE & Right common PV & 0.25 & $<12$ & 5 & Open surgical repair & Resolution of symptoms at $6 \mathrm{mths} F / U$ \\
\hline Liguori 1997 (20) & 63м & R-SLT & $22 \mathrm{mths}$ & TEE & URPV & 0.4 & - & $1,2,3$ & Intravenous diuretics & Resolution of symptoms at $6 \mathrm{mths} F / U$ \\
\hline Ruffini 1998 (8) & $39 \mathrm{M}$ & BLT & 11 days & TEE & URPV & - & - & 1 & Pulmonary lobectomy & Resolution of symptoms at $3 \mathrm{mths} F / U$ \\
\hline Huang 2000 (9) & $52 \mathrm{~F}$ & R-SLT & Intraoperative & TEE & LRPV & 0.25 & - & $1,2,4$ & None & Died on the 10th day \\
\hline Zimmerman 2009 (11) & $42 \mathrm{M}$ & R-SLT & 16 days & CTA & URPV & - & - & 1,3 & Balloon dilation and stent placement & Resolution of symptoms at $6 \mathrm{mths} F / U$ \\
\hline $\begin{array}{l}\text { González-Fernández } 2009 \\
\text { (10) }\end{array}$ & $49 \mathrm{~F}$ & L-SLT & $\begin{array}{l}\text { Early postoperative } \\
\text { period }\end{array}$ & $\begin{array}{l}\text { TEE and pulmonary } \\
\text { angiography }\end{array}$ & LLPV & 0.6 & 6 & 1,3 & Open surgical repair & Died on the $16^{\text {th }}$ post-operative day \\
\hline Pazos-Lopez 2010 (12) & $31 \mathrm{~F}$ & L-SLT & 15 days & TEE & LLPV & - & 20 & 1 & stent placement & Resolution of symptoms at 20 days $\mathrm{F} / \mathrm{U}$ \\
\hline Mydin 2012 (13) & $62 \mathrm{M}$ & R-SLT & $12 \mathrm{mths}$ & CTA & LRPV & 0.20 & 7 & 1 & Balloon dilatation & Recurrence at $2 \mathrm{mths}$ and died at $3 \mathrm{mths} F / U$ \\
\hline \multirow[t]{2}{*}{ Siddique 2013 (17) } & $25 \mathrm{M}$ & BLT & Intraoperative & TEE & Left common PV & - & "significant" & 1 & None & Further survived for 15 years \\
\hline & $46 \mathrm{~F}$ & BLT & Intraoperative & TEE & $\begin{array}{l}\text { Right and left } \\
\text { common PV }\end{array}$ & - & "significant" & 1 & Open surgical repair & Died on the $12^{\text {th }}$ postoperative day \\
\hline Lonial 2015 (14) & $64 \mathrm{~F}$ & R-SLT & $8 \mathrm{mths}$ & TEE and CTA & Right common PV & - & - & 2 & Balloon dilatation & Resolution of symptoms after dilatation \\
\hline Jobanputra 2017 (5) & $60 \mathrm{~F}$ & L-SLT & 14 mths & TEE and CTA & Left common PV & 0.35 & $12-16$ & 1 & Stent placement & Resolution of symptoms at $3 \mathrm{mths} F / \mathrm{U}$ \\
\hline Our new case & $31 \mathrm{M}$ & L-SLT & $19 \mathrm{mths}$ & CTA & ULPV and LLPV & $\begin{array}{l}0.20 \text { (ULPV); } \\
0.25 \text { (LLPV) }\end{array}$ & 40 & $1,2,3$ & Stent placement at ULPV & Resolution of symptoms at $10 \mathrm{mths} F / U$ \\
\hline
\end{tabular}

pulmonary vein; ULPV, upper left pulmonary vein; LLPV, lower left pulmonary vein.
pula 
China. However, the number of PVS cases is small and long-term follow-up data after stent placement is scarce. Studies with larger numbers of patients and long-term follow-up are needed to explore the best diagnosis and treatment for PVS following lung transplantation.

In conclusion, we reported a case of PVS and summarized the published studies to highlight the importance of timely identifying PVS after lung transplantation and the utility of CTA for diagnosis. In our patient, open surgery repair and retransplantation was avoided through stent implantation which suggests that stent implantation could be a promising therapeutic option for PVS patients after lung transplantation.

\section{Acknowledgments}

We thank Dr. Min Liu (Department of Radiology) for confirming the diagnosis by the radiographic findings.

Funding: This work was supported by the Non-profit Central Research Institute Fund of Chinese Academy of Medical Sciences (2019PT320020).

\section{Footnote}

Reporting Checklist: The authors have completed the CARE reporting checklist. Available at http://dx.doi.org/10.21037/ atm-20-3972

Conflicts of Interest: All authors have completed the ICMJE uniform disclosure form (available at http://dx.doi. org/10.21037/atm-20-3972). The authors have no conflicts of interest to declare.

Ethical Statement: The authors are accountable for all aspects of the work in ensuring that questions related to the accuracy or integrity of any part of the work are appropriately investigated and resolved. All procedures performed in studies involving human participants were in accordance with the ethical standards of the institutional and/or national research committee(s) and with the Helsinki Declaration (as revised in 2013). Written informed consent was obtained from the patient.

Open Access Statement: This is an Open Access article distributed in accordance with the Creative Commons Attribution-NonCommercial-NoDerivs 4.0 International License (CC BY-NC-ND 4.0), which permits the noncommercial replication and distribution of the article with the strict proviso that no changes or edits are made and the original work is properly cited (including links to both the formal publication through the relevant DOI and the license). See: https://creativecommons.org/licenses/by-nc-nd/4.0/.

\section{References}

1. de la Torre M, Fernández R, Fieira E, et al. Postoperative surgical complications after lung transplantation. Rev Port Pneumol (2006) 2015;21:36-40.

2. Kumar N, Essandoh M, Bhatt A, et al. Pulmonary cuff dysfunction after lung transplant surgery: a systematic review of the evidence and analysis of its clinical implications. J Heart Lung Transplant 2019;38:530-44.

3. Loyalka P, Cevik C, Nathan S, et al. Percutaneous stenting to treat pulmonary vein stenosis: after single-lung transplantation. Tex Heart Inst J 2012;39:560-4.

4. Li Y, Pan X, Wang C, et al. Stent implantation for severe pulmonary vein stenosis or occlusion secondary to atrial fibrillation ablation. Int J Cardiol 2020;301:85-9.

5. Jobanputra YB, Kapadia SR, Johnston DR, et al. Pulmonary vein stenosis following single-lung transplantation successfully treated with intravascular ultrasound-guided angioplasty and stent placement. Am J Case Rep 2017;18:1289-95.

6. Riley DS, Barber MS, Kienle GS, et al. CARE guidelines for case reports: explanation and elaboration document. J Clin Epidemiol 2017;89:218-35.

7. Low DE, Trulock EP, Kaiser LR, et al. Lung transplantation of ventilator-dependent patients. Chest 1992;101:8-11.

8. Ruffini E, Maggi G, Actis-Dato G, et al. Successful bilobectomy for pulmonary venous obstruction after bilateral lung transplantation. J Thorac Cardiovasc Surg 1998;116:648-9.

9. Huang YC, Cheng YJ, Lin YH, et al. Graft failure caused by pulmonary venous obstruction diagnosed by intraoperative transesophageal echocardiography during lung transplantation. Anesth Analg 2000;91:558-60.

10. González-Fernández C, González-Castro A, RodríguezBorregán JC, et al. Pulmonary venous obstruction after lung transplantation. diagnostic advantages of transesophageal echocardiography. Clin Transplant 2009;23:975-80.

11. Zimmermann GS, Reithmann C, Strauss T, et al. Successful angioplasty and stent treatment of pulmonary vein stenosis after single-lung transplantation. J Heart Lung Transplant 2009;28:194-8. 
12. Pazos-López P, Piñeiro-Portela M, Bouzas-Mosquera A, et al. Pulmonary vein stenosis after lung transplantation successfully treated with stent implantation. Circulation 2010;122:2745-7.

13. Mohamed Mydin MI, Calvert PA, Jenkins DP, et al. Percutaneous dilatation of right inferior pulmonary vein stenosis following single-lung transplant. Interact Cardiovasc Thorac Surg 2012;15:314-6.

14. Lonial K, Rashad MA, Valdez M, et al. Pulmonary venous stenosis, an uncommon cause of recurrent pleural effusions in lung transplant patients, A102. In: From me to you: new insights in lung transplant. Am Thorac Soc 2015;191:A2246.

15. Haydock DA, Trulock EP, Kaiser LR, et al. Management of dysfunction in the transplanted lung: Experience with 7 clinical cases. Ann Thorac Surg 1992;53:635-41.

16. Griffith BP, Magee MJ, Gonzalez IF, et al. Anastomotic

Cite this article as: Jing $\mathrm{L}$, Chen $\mathrm{W}$, Zhai Z, Pan X, Tao X, Cao L, Zhao L, Guo L, Liang C, Chen J, Wang C. Pulmonary vein stenosis after lung transplantation: a case report and literature review. Ann Transl Med 2021;9(2):181. doi: 10.21037/ atm-20-3972 pitfalls in lung transplantation. J Thorac Cardiovasc Surg 1994;107:743-53; discussion 753-4.

17. Siddique A, Bose AK, Özalp F, et al. Vascular anastomotic complications in lung transplantation: A single institution's experience. Interact Cardiovasc Thorac Surg 2013;17:625-31.

18. Clark SC, Levine AJ, Hasan A, et al. Vascular complications of lung transplantation. Ann Thorac Surg 1996;61:1079-82.

19. Michel Cherqui M, Brusset A, Liu N, et al. Intraoperative transesophageal echocardiographic assessment of vascular anastomoses in lung transplantation. Chest 1997;111:1229-35.

20. Liguori C, Schulman LL, Weslow RG, et al. Late pulmonary venous complications after lung transplantation. J Am Soc Echocardiogr 1997;10:763-7. 